7. Reprod. Fert. (1972) 30, 185-190

\title{
ULTRASTRUCTURAL CHANGES OF THE HAMSTER ENDOMETRIAL STROMAL CELL DURING THE LAST HALF OF PSEUDOPREGNANCY
}

\author{
T. H. BRINSFIELD, M. V. CLARK AND V. GERICH \\ United States Department of Agriculture, ARS, Animal Science Research Division, \\ Beltsville, Maryland 20705, U.S.A.
}

(Received 10th Fune 1971, accepted 24th Fune 1971)

\begin{abstract}
Summary. The ultrastructural changes of the endometrial stromal cells were quantified in twenty hamsters on Days 5, 6, 7 or 8 of pseudopregnancy. The mean percentage of cytoplasmic volume occupied by mitochondria, dense bodies, lysosomes and lipids each did not differ significantly during the 4 days $(P>0.05)$. The quantity of rough endoplasmic reticulum was not significantly different on Days 5 and $6(P>0.05)$, but significant increases occurred from Day 6 to Day 7 $(P<0.001)$ and from Day 7 to Day $8(P<0.001)$. The change in rough endoplasmic reticulum between Days 6 and 7 occurred during the stage of pseudopregnancy when the uterus influenced ovarian function.
\end{abstract}

\section{INTRODUGTION}

In some species, including the hamster, the uterus regulates the life-span of the corpus luteum (Duby, McDaniel, Spilman \& Black, 1969a). Although the precise rôle of the uterus in controlling ovarian function is unknown, Mazer \& Wright (1968) have shown that extracts of the hamster uterus on Day 6 or 7 of pseudopregnancy cause early regression of the corpora lutea when injected into hysterectomized pseudopregnant hamsters. The present study was made to determine the ultrastructural changes in endometrial stromal cells of the hamster during the stage of pseudopregnancy at which the uterus influences ovarian function.

\section{MATERIALS AND METHODS}

Twenty, non-parous, female hamsters, Mesocricetus auratus, of 10 to 12 weeks of age were used. Oestrus was checked daily with vasectomized males. A hamster was considered to be in oestrus when the lordosis reflex was observed. Pseudopregnancy was induced by mating oestrous females to vasectomized males (day of oestrus = Day 0 ). Hamsters failing to show the lordosis reflex on the 4th or 5th day following mating were considered to be pseudopregnant. Control animals not subjected to operation were used to establish the length of pseudopregnancy. Experimental animals were anaesthetized with $8 \mathrm{mg} \mathrm{Nem}$ butal (in $0.6 \mathrm{ml}$ saline) on the morning of Days $5,6,7$ or 8 of pseudopregnancy, 
a mid-ventral incision was made, and a $0.5-$ to $1.0-\mathrm{cm}$ segment from the centre of one uterine horn was removed and immediately placed in cold $1 \%$ osmium tetroxide in Millonig's buffer (Millonig, 1961) at $\mathrm{pH} \mathrm{7.4.} \mathrm{The} \mathrm{re-}$ mainder of the uterus was then removed, along with a portion of the cervix, and the incision was closed. Five hamsters were hysterectomized on each of the 4 days of pseudopregnancy. Oestrus was checked daily to determine the effect of hysterectomy on the length of the operative pseudopregnancy. The appearance of the lordosis reflex was used as the end point for determining the length of pseudopregnancy.

Within 5 min after the specimen of the uterine tissue from each hamster was placed in the fixative, the endometrium was dissected from the myometrium and twenty specimens of the endometrium measuring approximately $2 \mathrm{~mm}^{3}$ were fixed for $1 \mathrm{hr}$ in $1 \%$ osmium tetroxide in Millonig's buffer at $4^{\circ} \mathrm{C}$. Following fixation, the tissue was dehydrated in ascending grades of ethanol and propylene oxide, and ten of the twenty specimens were randomly selected and embedded in an Araldite-Epon resin mixture.

For preliminary examination of the endometrium $1 \mu \mathrm{m}$ thick sections from four randomly selected specimens were cut, stained with toluidine blue and examined with a light microscope to select the desired area for ultra-thin sectioning and electron microscopy. Thin sections were cut from each of the four blocks with a LKB Ultrotome or a Sorvall Porter-Blum Ultramicrotome. Sections were picked up on unsupported 200-mesh copper grids, stained for $1 \mathrm{hr}$ in methanolic uranyl acetate stain (Stempak \& Ward, 1964), examined and photographed in a Philips EM 200 electron microscope at initial magnifications of $\times 2300$ to $\times 3800$ and enlarged photographically 6.4 times with final magnification of $\times 14,720$ to $\times 24,320$.

For quantitative analysis of cellular ultrastructure, thin sections were cut from three blocks of embedded endometrium from each hamster, picked up on unsupported 200-mesh copper grids and stained with methanolic uranyl acetate. The cells to be quantified were randomly selected by photographing the cell appearing in the uppermost left-hand corner of the grid square. The only other criteria used for the selection of cells to be quantified were that the nucleus be visible and that the cell show no fixation or sectioning damage. Two to four cells from each of the three blocks were photographed. A total of ten cells from each of the twenty hamsters were measured quantitatively. The cells were photographed with a Philips EM 200 electron microscope at initial magnification of $\times 9100$ and enlarged photographically $\times 2.5$ with final magnification of $\times 22,750$. At this magnification, one entire cell could generally be recorded on one electron micrograph.

The technique of linear analysis was employed (Loud, 1962; Loud, Barany $\&$ Pack, 1965) for the approximate quantitative measurement of the percentage volume of the cell occupied by mitochondria, dense bodies, lysosomes, lipids and rough endoplasmic reticulum in relation to the total cell cytoplasm. The measurements were carried out on $8 \times 10$ in. enlarged prints of the electron micrographs. A square grid of white lines was superimposed on each micrograph at the time of the photographic printing by lengths of 7-mil wire attached to a frame on the enlarging easel. The lengths of wire were spaced exactly 


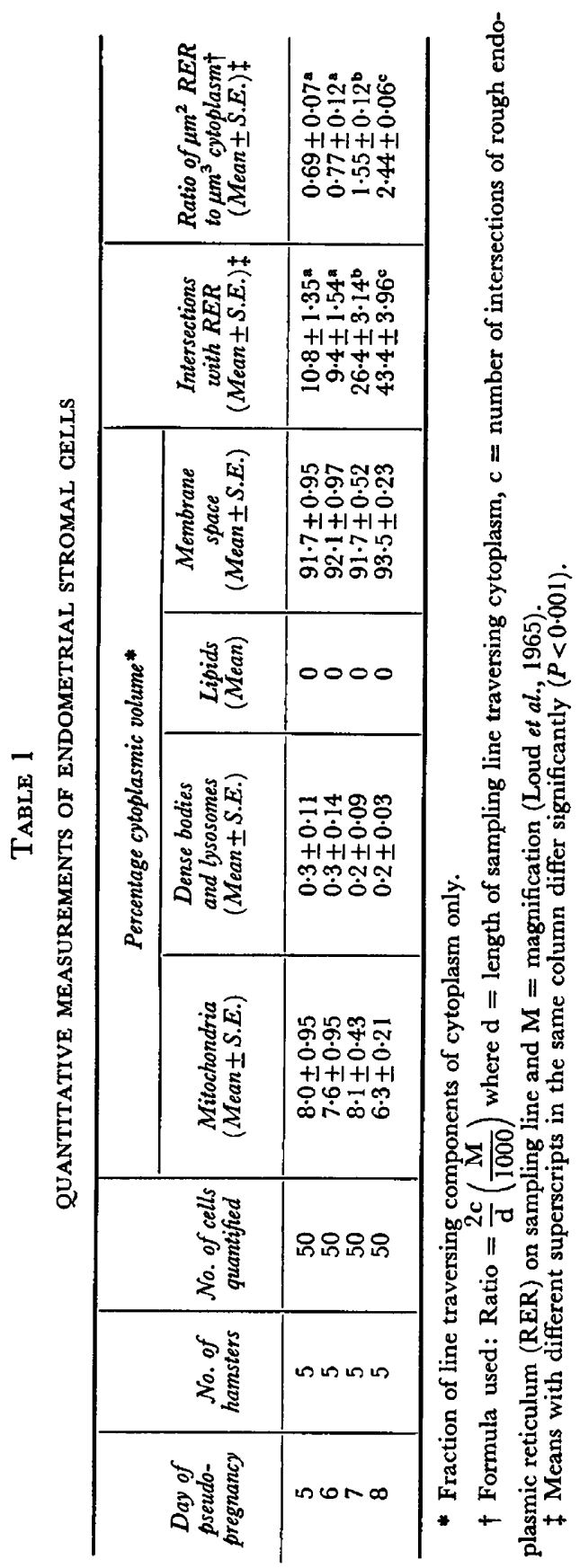


$2.54 \mathrm{~cm}$ apart in both vertical and horizontal directions resulting in $2.54 \mathrm{~cm}$ squares over the entire $8 \times 10$ in. photograph. The percentage of cytoplasmic volume occupied by mitochondria, dense bodies, lysosomes and lipid was then determined by measuring the portion of the line overlying each of these components in relation to that part of each line overlying the entire cytoplasm. That portion of the lines not lying over the above cell constituents was termed 'membrane space' (Loud, 1962), and included the remainder of the cytoplasm in which the principal structures were membranes of the endoplasmic reticulum.

For quantitative measurements of the rough endoplasmic reticulum, the method and formula (Table 1) as set forth by Loud et al. (1965) was employed. In this analysis, the total number of intersections of rough endoplasmic reticulum membrane along the length of all lines superimposed over each cell was determined in relation to the total length of the lines overlying the entire cytoplasm of each cell. Using these two measurements, in addition to the final magnification, the average surface to volume ratio of the number of $\mu \mathrm{m}^{2}$ of rough endoplasmic reticulum surface per $\mu \mathrm{m}^{3}$ of cytoplasm was determined, which takes into account the quantity of cytoplasm.

\section{RESULTS}

\section{Effect of hysterectomy on ovarian function}

The mean length of pseudopregnancies in intact control hamsters was $9 \cdot 0$ days. Removal of the uterus on Day 7 or 8 of pseudopregnancy also resulted in cycle lengths of 9.0 days, but removal of the uterus on Day 5 or 6 extended the cycles to 22.0 and 21.8 days, respectively. These results indicate that by Day 7 the uterus had participated in the luteolytic process which normally causes the regression of the corpora lutea at the end of pseudopregnancy.

\section{Ultrastructure of the endometrial stromal cells}

Table 1 includes the measurements obtained from 200 endometrial stromal cells, representing fifty cells from each of the 4 days of pseudopregnancy. The mean percentage of cytoplasmic volume occupied by the mitochondria, dense bodies and lysosomes, lipids and membrane space was not significantly different during the 4 days of pseudopregnancy studied $(P>0.05)$. However, the number of intersections of rough endoplasmic reticulum (RER) increased significantly from Day 6 to Day $7(P<0.001)$ and increased further from Day 7 to Day $8(P<0.001$, Table 1$)$. When the ratio of RER to the quantity of cytoplasm was considered, significant differences again were found between Days 6 and $7(P<0.001)$ and between Days 7 and $8(P<0.001)$.

\section{EXPLANATION OF PLATE 1}

Fic. 1. Day-5 endometrial stromal cell. Rough endoplasmic reticulum (RER) is scattered and predominantly tubular in form. N, nucleus; G, Golgi complex with associated vesicles; $\mathrm{Ce}$, centriole; $\mathrm{DB}$, dense body; $\mathrm{M}$, mitochondria; Ly, lysosomes. $\times 9804$.

Fig. 2. Day-6 endometrial stromal cell. Rough endoplasmic reticulum (RER) is somewhat more abundant than at Day 5 . Nucleus $(N)$ has well-defined nucleolus (Nu). G, Golgi complex; M, mitochondria. $\times 9701$. 
PLATE 1
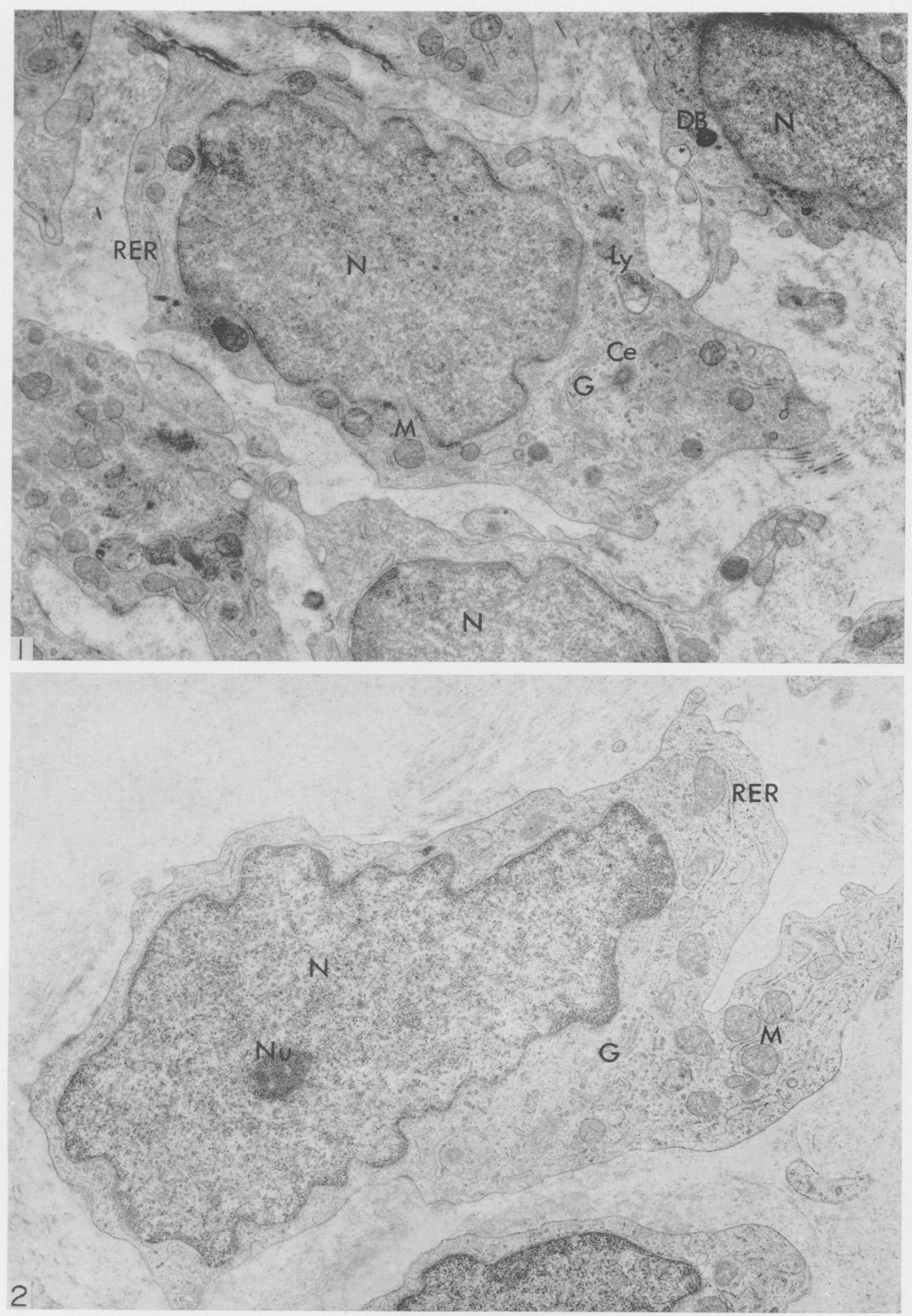

(Facing p. 188) 
PI.TCE?
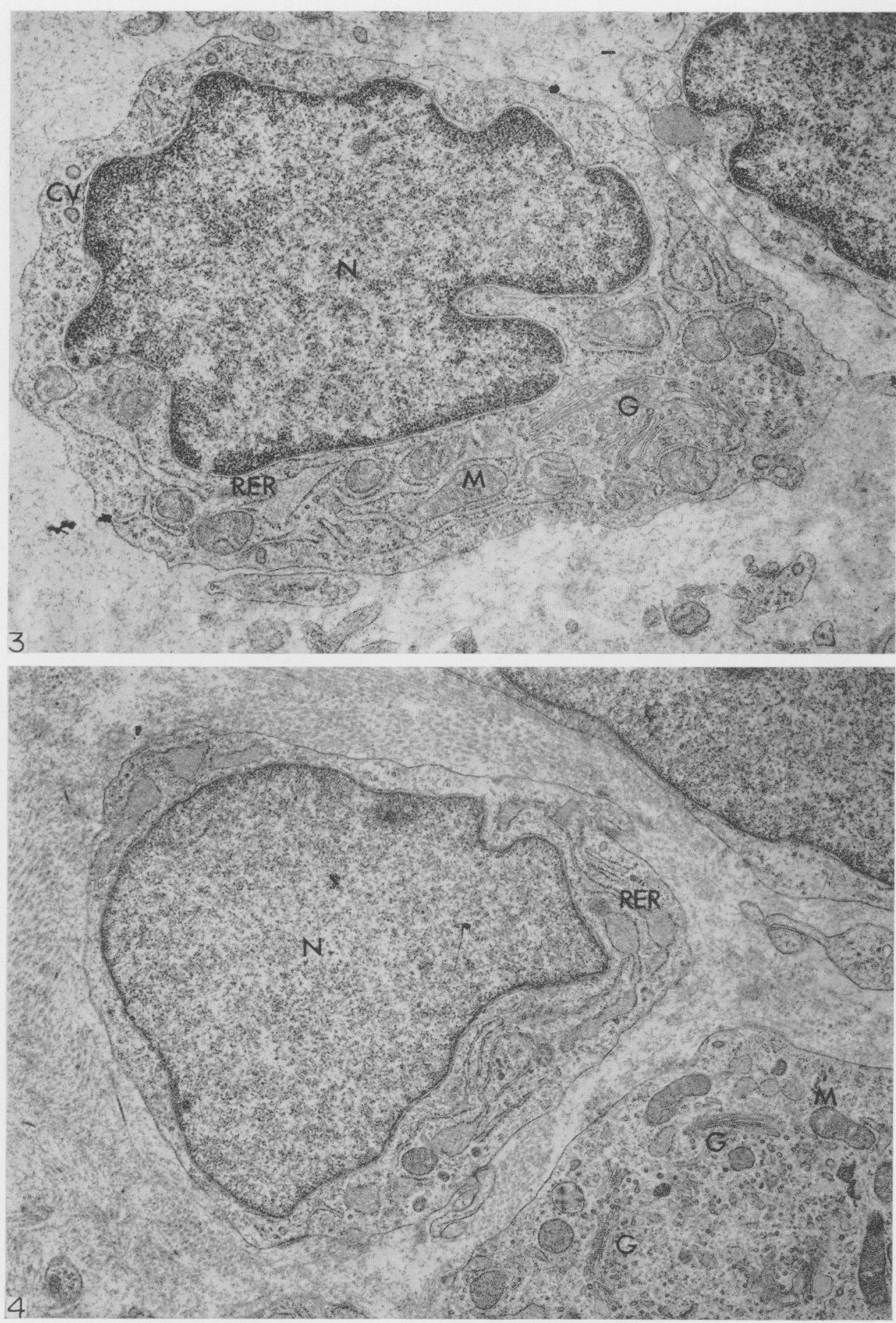

(Facing p. 189) 
Statistical analysis indicated that there were no significant differences between replicates in any of the measurements made in this study $(P>0.05)$. In addition to the quantitative change in RER, the form of RER also changed during Days 5 to 8 of pseudopregnancy. On the 5 th and 6 th days, the RER was predominantly tubular in form and closely associated with the mitochondria (Pl. 1, Figs. 1 and 2). By Days 7 and 8, the cisternae of the RER became highly dilated, and extensive tubular structures had developed (Pl. 2, Figs. 3 and 4). An electron-dense material was present in the cisternae of the RER on Days 7 and 8.

The Golgi complex was not quantified in the present study but was included in the 'membrane space' (Table 1). The complex was extensively developed in the endometrial stromal cells on each day of pseudopregnancy (Plates 1 and 2, Figs. 1 to 4 ). Numerous vesicles in various forms and sizes were always associated with the Golgi complex, some vesicles being coated with an electrondense material.

Dense bodies and lysosomes were found in the cytoplasm of stromal cells during each day of pseudopregnancy. Dense bodies and lysosomes were combined in the quantitative measurements since it is difficult to distinguish clearly some dense bodies from lysosomes on a morphological basis. Electrondense structures without the presence of vacuoles were considered dense bodies, while lysosomes varied from simple structures containing vacuoles to structures containing cellular débris (Pl. 1, Fig. 1).

\section{DISCUSSION}

The increase in quantity and the change in form of RER in the stromal cells of the endometrium during Days 5 to 8 of pseudopregnancy may have been the cause, the consequence, or both, of changes in ovarian function. The increase in RER, noted initially by Day 7 which increased further by Day 8 , may have been the consequence of changes in ovarian secretions after the uterus had initiated luteal regression.

Recent evidence has shown that, by Day 7 of pseudopregnancy, luteolysis in the hamster has begun since weights of corpora lutea begin to decline (unpublished data) and plasma progesterone levels have decreased significantly (McDaniel, 1970). In the present study, the initial increase in quantity, and the elongation and dilatation of RER occurred within the 24-hr period between the morning of Day 6 and the morning of Day 7 of pseudopregnancy. This period of time coincides with the stage of pseudopregnancy at which removal of the uterus no longer extended pseudopregnancy, indicating that the uterus probably initiated luteal regression between Days 6 and 7. Day 6 is also the

\section{EXPLANATION OF PLATE 2}

FIG. 3. Day-7 endometrial stromal cell. Note increased quantity and dilatation of rough endoplasmic reticulum (RER). N, nucleus; G, Golgi complex; GV, coated vesicles; $\mathrm{M}$, mitochondria. $\times 14,705$.

FIG. 4. Day-8 endometrial stromal cells showing rough endoplasmic reticulum (RER) with dilated ends containing dense material. $N$, nucleus; $G$, Golgi complex; $M$, mitochondria. $\times 10,416$. 
initial stage of pseudopregnancy at which the hamster uterus contains an extractable luteolytic substance (Mazer \& Wright, 1968).

Results from previous studies suggest that the changes in the RER noted in the present experiment were caused by oestrogen acting on the uterus. For example, dilated RER in the stromal cells has been noted previously in the oestrogen-treated rat (Ross \& Klebanoff, 1967). The increase in quantity and swelling of RER indicates protein synthesis, which occurs during the first $24 \mathrm{hr}$ after oestrogen administration (Segal \& Scher, 1967). Duby, McDaniel, Spilman \& Black (1969b) have shown that, by Day 7, the hamster uterus iricreases in wet weight, a well-recognized effect of oestrogen. These findings suggest that by Day 7 of pseudopregnancy, the hamster uterus is probably under the influence of oestrogenic stimulation.

Further work will be required to elucidate the cause and effect relationships involved in nearly concurrent changes in uterine and ovarian function.

\section{AGKNOWLEDGMENTS}

The authors wish to acknowledge the technical assistance of Miss Pamela Myerovitz and to express their appreciation to Dr H. W. Hawk for suggestions in the preparation of this manuscript

\section{REFERENCES}

Duby, R. T., McDaniel, J. W., Spilman, G. H. \& Black, D. L. (1969a) Utero-ovarian relationships in the golden hamster. I. Ovarian periodicity following hysterectomy. Acta endocr., Copenh. 60, 595.

Duby, R. T., McDaniel, J. W., Spilman, C. H. \& Black, D. L. (1969b) Utero-ovarian relationships in the golden hamster. III. Influence of uterine transplants and extracts on ovarian function following hysterectomy. Acta endocr., Copenh. 60,611.

Loun, A. (1962) A method for the quantitative estimation of cytoplasmic structures. F. Cell Biol. 15, 481.

Loud, A. V., BARANY, W. C. \& PACK, B. A. (1965) Quantitative evaluation of cytoplasmic structures in electron micrographs. Lab. Invest. 14, 258.

McDaniel, J. W. (1970) Progesterone concentration in the plasma of the Syrian Hamster during pseudopregnancy. (Abstract). 3rd Ann. Meet. Soc. Study Reprod., p. 34.

MAZER, R. S. \& WRIGHT, P. A. (1968) A hamster uterine luteolytic extract. Endocrinology, 83, 1065.

Millonig, G. (1961) Advantages of a phosphate buffer for $\mathrm{OsO}_{4}$ solutions in fixation. F. appl. Physics, $32,1637$.

Ross, R. \& KLebanoff, S. J. (1967) Fine structural changes in uterine smooth muscle and fibroblasts in response to estrogen. 7. Cell Biol. 32, 155.

SEgAL, S. J. \& Scher, W. (1967) Estrogens, nucleic acids and protein synthesis in uterine metabolism. In: Cellular Biology of the Uterus, p. 137. Ed. Ralph M. Wynn. Meredith Publishing Company, New York.

Stempak, J. G. \& WARD, R. T. (1964) An improved staining method for electron microscopy. F. Cell Biol. 22, 697 . 